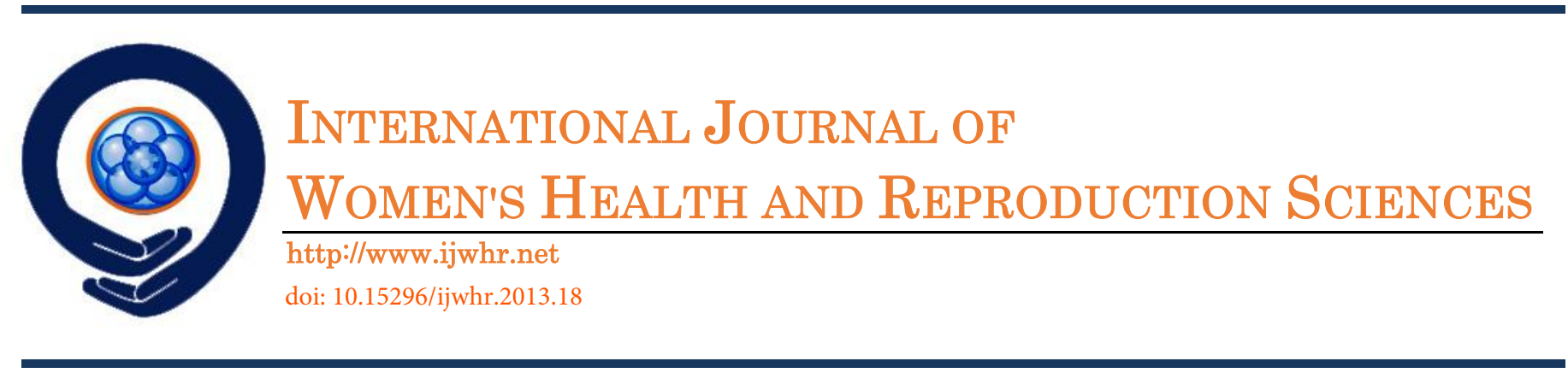

\title{
Severe Hydronephrosis Caused by Uterine Prolapse with Non Specific Symptoms and Normal Renal Function
}

\author{
Muammer Altok $^{1 *}$, Ali Feyzullah Şahin², Mehmet Umul ${ }^{1}$, Mustafa Güneş${ }^{1}$
}

\begin{abstract}
Article History:
Received July 2013

Accepted September 2013

Available online September 2013

Keywords:

Single Incision Mini Sling

Surgical Treatment

Stress Urinary Incontinence

Transobturator Tape

Corresponding Author:

Muammer Altok, Suleyman

Demirel University, Faculty of

Medicine, Department of Urology,

32260 Isparta-Turkey.

Tel: +902462119275

Email: dr_muammer@yahoo.com
\end{abstract}

\begin{abstract}
:
Pelvic organ prolapse (POP), is the descent of pelvic organs (bladder, uterus, rectum) until protrusion through the vagina and related to the loss of normal attachment and support of the pelvic floor. Pelvic organ prolapse (POP) is a common problem in elderly women and usually causes various urologic symptoms. One of the most important complications of POP is hydronephrosis. The hydronephrosis is usually mild. Severe hydronephrosis is very rare. Hydronephrosis caused by POP may lead to renal dysfunction and serious urinary infections. Early detection and treatment is very important for preventing irreversible renal damage.

Hereby, we report a case of 65-years-old woman who had massive uterine prolapse with silent severe bilateral hydronephrosis. She had no complaint except a protruding tissue out of her vagina. Renal function was normal and hydronephrosis was detected incidentally. The symptoms may be non-specific and silent until a serious infection or renal dysfunction. Therefore patients with a POP especially with severe POP need to have evaluation and imaging about the condition or the urinary system before a serious pathology occur.
\end{abstract}

1- Süleyman Demirel University, Faculty of Medicine, Department of Urology, Isparta-Turkey.

2- Şifa University, Faculty of Medicine, Department of Urology, İzmir-Turkey. 


\section{Introduction:}

Pelvic organ prolapse (POP), is the descent of pelvic organs (bladder, uterus, rectum) until protrusion through the vagina and related to the loss of normal attachment and support of the pelvic floor. The prevalence of POP in the general population is $37 \%$, whereas it is rising to $64.8 \%$ in elderly women.1 Hydroureteronephrosis associated with uterine prolapse was first described in 1824 and reviewed in 1931 by Frank. 2 The degree of the hydronephrosis is usually mild. Severe hydronephrosis is very rare in POP patients.

\section{CASE REPORT :}

A 65-years-old woman with a history of 6 pregnancies, 3 vaginal deliveries (3 miscarriages) consulted for a protruding tissue out of the vagina ongoing for the last 3 years. She was referred to Urology Service with grade-III hydronephrosis identified by ultrasonography. She had occasionally urge incontinence, difficulty in voiding and rarely minimal left flank pain. Values of plasma creatinine was $0.7 \mathrm{mg} / \mathrm{dL}$ (normal range: $0.6-1.1 \mathrm{mg} / \mathrm{dL}$ ) and value of plasma urea was $38 \mathrm{mg} / \mathrm{dL}$ (normal range: $14-40 \mathrm{mg} / \mathrm{dL}$ ). The urine analysis was normal. Pelvic examination revealed a massive total uterine prolapse (Figure 1). There was no history of any surgery or trauma.

Abdominal CT and MRI were performed (Figure 2, 3, 4). CT and MRI showed bilateral severe hydronephrosis with dilated ureters prolapsing out from the pelvis with accompanying a total uterine prolapse.

\section{Discussion:}

Pelvic organ prolapse usually causes various symptoms as voiding dysfunction (obstructive urinary symptoms, retention, frequency, urgency, and incontinence), defecation problems (tenesmus, fecal incontinence, and constipation), flank pain or pelvic discomfort.

One of the most serious complications of POP is hydronephrosis and may lead to renal infection, renal dysfunction and irreversible renal damage if left untreated. The prevalence of hydronephrosis in patients who underwent surgery for POP was reported between $7 \%$ to $17 \%$ in the literature.3,4 In a prospective study it was reported as 10,3\%.5 Severe hydronephrosis was very rare and reported between 1.3\% and $2.1 \% .4,5$

There is a correlation between the degree of prolapsus and hydronephrosis.4,5 Hydronephrosis was reported 5\% in stage-1, $5.1 \%$ in stage- $2,17.7 \%$ in stage- 3 and $33.3 \%$ in stage-4 prolapse.5 Patients who had stages 3 to 4 POP were 3.4 times more likely to have hydronephrosis than those who had stage 1 to 2 prolapse. 5

Our patient had a massive total uterine prolapsed with severe hydronephrosis but her symptoms were not clear and she had any complaint except the protruding tissue out of the vagina. Hydronephrosis was detected incidentally by a routine ultrasonographic evaluation. Her kidney function tests and urine analysis was normal. There was no correlation between the uterine prolapsus degree, hydronephrosis and semptoms or laboratory findings. Urinary changes occurred silently.

Patients with hydronephrosis were significantly older and had higher parity. 5 Shuk et al reported an overall age of 71,8 and an overall parity of 4,3 in patients with hydronephrosis. 5 Our patient was 65 years old and had 3 parities.

The mechanism of hydronephrosis is not clear. Possible factors include compression of the ureters by the uterine vessels6, the levator ani sling7, or even the uterine fundus.8 In our case the hydronephrosis was likely to be the result of distortion of vesicoureteric junctions and compression of the uterus and bladder (Figure 2, 4).

Complete resolution of the hydronephrosis after treatment is higher and was reported as $95,2 \% .5$ POP should be treated as soon as possible before irreversible renal damage occurs.

\section{Conclusion :}

Pelvic organ prolapse may lead to renal dysfunction or serious urinary infection. The symptoms may be non-specific and silent until a serious infection or renal dysfunction. In the literature the renal function and the condition of the kidney was usually evaluated after a serious problem like renal dysfunction, uremia, urosepsis.9,10 Therefore patients with a POP especially 
with severe POP need to have evaluation and imaging about the condition or the urinary system before a serious pathology occur. Ultrasonography is a cheap, easy and effective modality, it could be a good choice for the evaluation of the kidneys especially in high grade POP. Early recognition and correction has great importance to prevent irreversible renal damage.

Evaluation of the kidney and ureter in POP patients before surgery may be important also for avoiding ureteral damage and other iatrogenic complications during surgery.

Conflict of interest:

The authors declare that they have no conflict of interest.

Figure captures:

Figure 1: Macroscopic view of massive uterine prolapse.

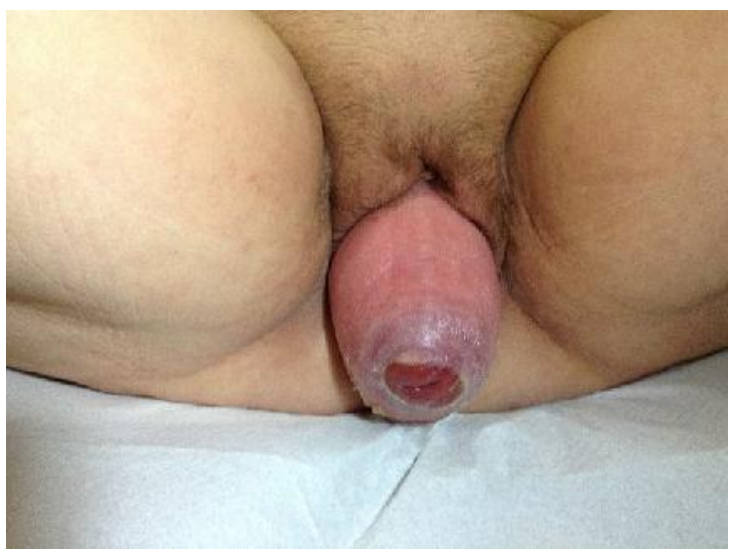

Figure 2: Coronal section of CT image reveals bilateral hydronephrosis and ureteral distortion due to uterine prolapse.

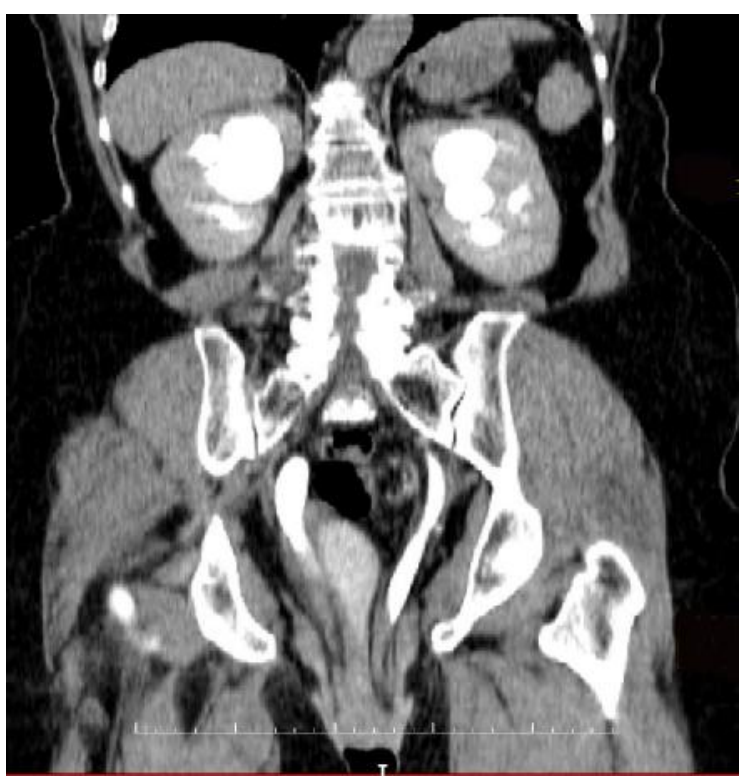

Figure 3: Reconstructive Coronal section of CT image reveals bilateral hydroureteronephrosis.

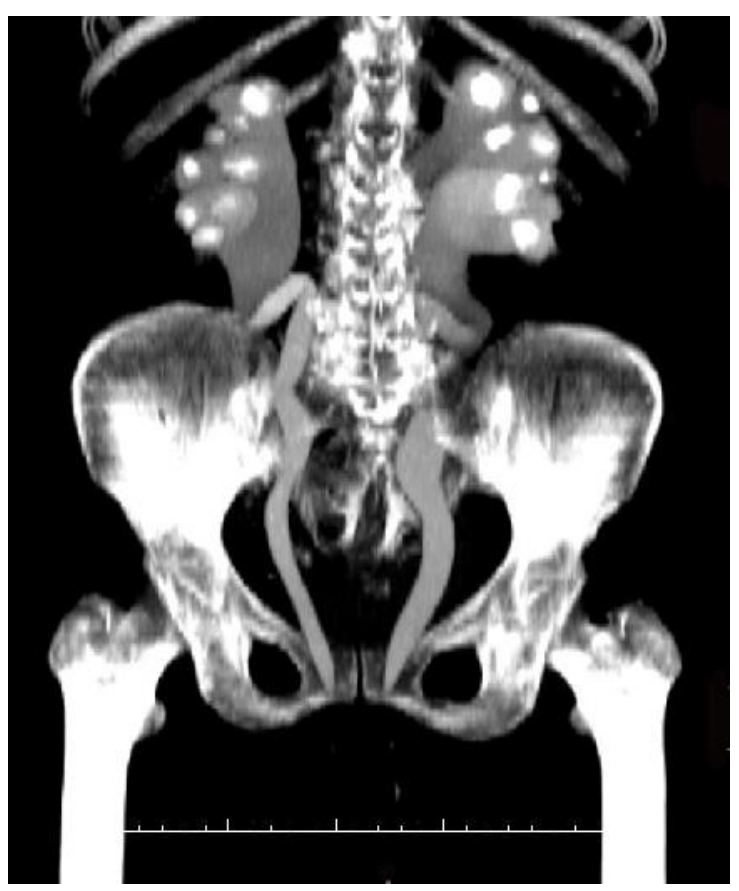

Figure 4: Sagittal section of MR image shows the relation between distal ureter and prolapse.

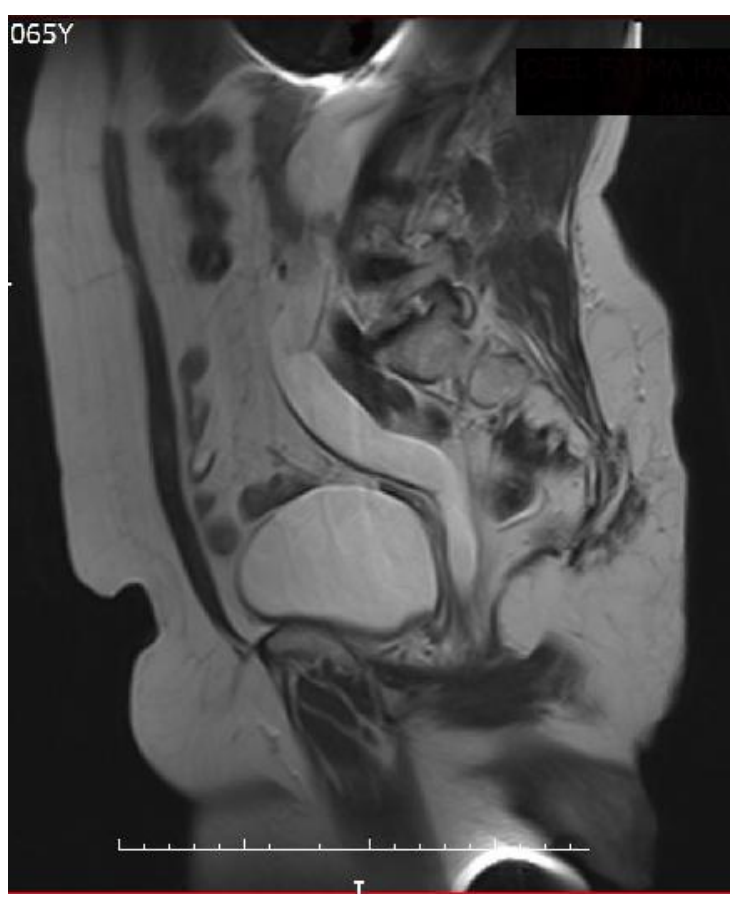




\section{References:}

1. Gerten KA, Markland AD, Lloyd LK, et al. Prolapse and incontinence surgery in older women. J Urol. 2008;179:2111-2118.

2. Frank, R.T. Fatal uremia due to complete prolapse of the uterus. Am J Obstet Gynecol $1931 ; 22: 270-272$.

3. Beverly CM, Walters MD, Weber AM, Piedmonte MR, Ballard LA (1977) Prevalence of hydronephrosis in patients undergoing surgery for pelvic organ prolapse. Obstet Gynecol 90: $37-41$

4. Gemer O, Bergman M, Segal S (1999) Prevalence of hydronephrosis in patients with genital prolapse. Eur J Obstet Gynecol Reprod Bio 86:11-13

5. Shuk YAH, Shing CSC, Suk YJL et al. A prospective study on the prevalence of hydronephrosis in women with pelvic organ prolapsed and their outcomes after treatment. Int Urogynecol J 2011; 22:1529-1534.

6. Brettauer J, Rubin IC. Hydroureter and hydronephrosis: a frequent secondary finding in cases of prolapse of the uterus and bladder. Am J Obstet Gynecol 1923; 6:696-708.

7. Halban J, TandlerJ. Anatomie und Atiologie der Genital prolapsed beimWeibe.Vienna and Leipzig: W Braumuller,1907;176-80.

8. Hadar H, Meiraz D. Total uterine prolapse causing hydroureteronephrosis. SurgGynecolObstet 1980;150:711-4.

9. Chuang FR, Lee $\mathrm{CH}$, Chen $\mathrm{CS}$ et al. Bilateral moderate hydroureteronephrosis due to uterine prolapse: Two case reports and review of the literature. Renal Failure, 2003; 25(5): 879-884

10. Sanai T, Yamashiro Y, Nakayama $M$ et al. End-stage renal failure due to total uterine prolapse. Urology 2006; 67:622 e5-622 e7 